\title{
PREDICTIVE BIOLOGICAL MARKERS FOR ANASTOMOTIC LEAKAGE AFTER CURATIVE SURGERY FOR COLORECTAL CANCER
}

\author{
ERIKA BIMBÓ-SZUHAI ${ }^{1}$, ADRIAN MAGHIAR ${ }^{2}$, ANCA HUNIADI ${ }^{3}$, MIRCEA ȘANDOR $^{4}$, MIHAI \\ BOTEA $^{5}$, CODRUȚA MACOVEI $^{6}$, CORINA BEIUȘAN $^{7}$, CLAUDIA TEODORA JUDEA PUSTA $^{8}$ \\ 1,2,3,4,5,6,7,8 University of Oradea
}

\begin{abstract}
Keywords: $\quad$ colorectal Abstract: anastomotic leakage is one of the most important postoperative complications for colorectal cancer, anastomotic cancer patients undergoing curative surgery. Early recognition of patients in risk would be essential leakage, CRP level, for preventing the high mortality rates associated with these complications. C reactive protein (PCR), granulocyte/lymphocyte tumour necrosis factor (TNF-alpha), cortisol levels and granulocyte/lymphocyte ratio (G/L) were ratio compared in this period in patients who developed leakage vs patients without this complication. Material and methods: 52 colorectal cancer patients who underwent elective surgery in a private clinical hospital were evaluated preoperatively and postoperatively for the patients. Results: 14 patients $(26,9 \%)$ developed clinically significant anastomotic leakage. The best cut-off value for preoperative $G / L$ ratio of 5,8 had sensitivity of $71,43 \%$ and specificity of $73,68 \%$. Conclusions: Preoperative $G / L$ ratio can be used as a largely available tool for identifying the colorectal cancer patients at high risk for anastomotic leakage.
\end{abstract}

\section{INTRODUCTION}

Anastomotic leakage is a severe complication after colorectal surgery associated with a high perioperative mortality and morbidity, prolonged hospital admittance and higher care expenses. This complication is also an independent risk factor for a reserved prognosis in patients undergoing curative colorectal surgery procedure, resulting in a higher chance of local recurrence and general survival. There are multiple associated risk factors for anastomotic leakage, and as a consequence it is complicated to predict this complication for a certain patient.

Despite evolution in understanding risk factors for anastomotic leakage and surgical technique development, anastomotic leakage remains an important complication that occurs in some patients without an evident cause and without any known risk factors. Early diagnosis of anastomotic leakage should be possible as a way to reduce morbidity and associated mortality.

The role of cytokine and Alpha-TNF, interleukin 1 and interleukin 6 in stimulation of production of acute phase protein is well-known and its release in the postoperative phase could be correlated with surgical stress extension and increased rate of complications.

Reactive C protein (PCR), is an acute phase protein synthesized in the liver- which was intensively studied as a predictive marker for postoperative complication in abdominal surgery(1).

Due to relatively short half-life (19 h), PCR is a trustful marker for predicting systemic inflammatory response secondary to surgical procedures and even for complications, with a sharp drop in his rates as the patient recovers.(2) As for anastomotic leakage secondary to curative colorectal surgical procedure it is well known that increasing PCR levels in $2-3$ days in postoperative period is associated with higher risk of developing this complication.(3)

Another marker for systemic inflammatory response could be leukocyte formula.(4) It is known that leukocytes express cholinergic and adrenergic receptors.(5) As a consequence, changes in the vegetative nervous system, as in stress inflammation may affect leukocytes that carry cholinergic and adrenergic receptors.(6) It is believed that during operation, neutrophils and lymphocytes are differently affected so they intermediate different actions.

An inborn immune answer against different stimuli has granulocytosis as response, and lymphopenia also observed in patients with cancer in advanced phases.(7) Granulocytes and lymphocytes show changes as a response to biochemical mediators and stress hormones equally in quantity and quality. Improving clinical status after surgical procedures also concur increasing lymphocyte level and decreasing granulocyte levels at the same time.(8)

Based on these observations it is reasonable to presume its clinical value for granulocytes / lymphocytes rates.

\section{AIM}

Under the circumstances we proposed that biomarkers identification which permit rapid patient check up for high risk of developing anastomotic leakage after a curative surgical procedure for colorectal cancer.

Analysing the current literature and the current routine available biological markers in our surgery department we proposed the next following markers in pre- and post-operative day 1: alpha TNF ,serum cortisol levels, PCR levels and the granulocytes/lymphocytes rates $(\mathrm{G} / \mathrm{L})$.

'Corresponding author: Bimbó-Szuhai Erika, Str. Delavrancea, Nr. 13, Ap. 2. 410058, Oradea, România, E-mail: bszera@ gmail.com, Phone: +40740 154365

Article received on 25.11.2020 and accepted for publication on 26.02.2021 


\section{CLINICAL ASPECTS}

\section{MATERIALS AND METHODS}

Our clinical study, a prospective observational cohort study, has been conducted in the Surgery Department of Oradea Pelican Clinical Hospital between January 2015-August 2019. The research has been analysed and approved by the hospital's ethics committee and in case of identifying an eligible patient, we proceeded to present and sign an informed consent protocol. Patients' inclusion criteria for colorectal cancer confirmed after colonoscopy and histological confirmed results.

Exclusion criteria: Age under 18, pregnant patient, evident distant metastasis, any pre-existing inflammatory bowel disease, or rheumatoid arthritis, clinical evident preoperative infection, postoperative infection from another proved source different form anastomotic leakage. The blood samples were taken a-jèun, by puncturing a peripheral vein. The blood sampling was made by blood prelevation from a vein in a vacutainer with anticoagulant for blood samples for whole blood count-leukocytes formula (for $\mathrm{G} / \mathrm{L}$ ratio), and in vacutainer without anticoagulant in case of biochemical determinations such as alpha-TNF, serum cortisol levels and CPR levels. The following analysing methods were applied are automated analyser on fluorescent principle in cytometric flux using semiconductor LASER, and hydrodynamic focusing for complete blood count for leukocytes formula, chemiluminescent immunochemical detection method for alpha-TNF, latex immunoturbidimetric method for CRP, and immunochemical detection method by electrochemiluminescence for serum cortisol levels. Besides these lab findings, the study file has been completed with the following date for each patient enrolled: age, sex, environment, tumoral stage (Duke's classification), type of surgical procedure- classic or laparoscopic approach- and tumoral site. Anastomotic leakage was diagnosed by clinical findings of a peritonitis and/or evident free fecaloide liquid in abdominal cavity or on the drain tube confirmed through abdominal and pelvic CT with IV contrast substance or anorectal. The two groups were built based on this factor. Group A with anastomotic leakage and Group B without anastomotic leakage diagnosed.

Statistical analyses: Continuous variables will be presented under an arithmetic average, respectively geometrical one with a standard deviation - in brackets - having normal distribution some of them after a logarithmic transformation. Categorical variables will be described by number of observations and percentages in brackets-significant differences from statistical point of view where considered at lower values then 0.05 off zeros hypothesis(p). Statistical tests were done with the help of $\mathrm{MedCalc}^{\circ}$ version 12.5.0.0 (MedCalc $^{\circ}$ Software, Mariakerke, Belgium). Comparison of the two groups for categorical variables has been done with chi square cast and chi square cast with Yates correction when used in table $2 \times 2$; and for continuous variables with the help of student test for independent groups (with or without logarithmic transformation as needed after case). For correlation check-up in between biological markers it has been used.

Pearson correlation factor. ROC curves (receiver operator characteristic) and the area under the curves (AUC) were used to compare diagnostic tests and for determination of limit values that indicates the risk of anastomotic leakage. ROC curves are points terminated by real positive values (sensitive) and false positive one (1-specificity) for each value detected (level of PCR or $\mathrm{G} / \mathrm{L}$ rate).

Limitations of the study: The power of the study statistically depends on the number of cases for each group and the number of patients with postoperative complication. Fortunately, this number was not high, but this aspect of the study limits the importance of the conclusion referring to risk factors. Monitoring the evolution of biological markers during several days in the post-operative period would increase the precision of predictors for anastomotic leakage but also the correlation in between pre-and postoperative biological markers. It is possible that some patients may have a subclinical anastomotic leakage undiagnosed which may imply inevitable statistical error. But this subclinical anastomotic leakage usually has favourable evolution without treatment and the purpose of our study is to identify the patients with complications which in turn implies increased morbidity and mortality.

\section{RESULTS}

14 patients $(26,9 \%)$ from 52 patients enrolled in the study, presented anastomotic leakage in the postoperative period. The main characteristic for the two groups are presented in the table no. 1.

Table no. 1. Main characteristic for two groups

\begin{tabular}{|c|c|c|c|}
\hline Basic features & $\begin{array}{l}\text { Lot A } \\
n=14\end{array}$ & $\begin{array}{l}\text { Lot B } \\
n=38\end{array}$ & $\begin{array}{r}\mathbf{p} \\
\text { (statistical } \\
\text { significance) }\end{array}$ \\
\hline $\operatorname{Sex}(\mathrm{M} / \mathrm{F})$ & $10 / 4$ & $26 / 12$ & 0,8964 \\
\hline $\begin{array}{l}\text { Age (year) - average } \\
( \pm \mathrm{DS})\end{array}$ & $\begin{array}{c}62,42 \\
( \pm 12,04)\end{array}$ & $\begin{array}{c}70,26 \\
( \pm 11,31)\end{array}$ & $\mathbf{0 , 0 3 4 2}$ \\
\hline Resident (U/R) & $4 / 10$ & $16 / 22$ & 0,5697 \\
\hline $\begin{array}{c}\text { Tumor stage (\%) } \\
\text { Dukes A } \\
\text { Dukes B } \\
\text { Dukes C }\end{array}$ & $\begin{array}{l}2(14,4 \%) \\
6(42,8 \%) \\
6(42,8 \%)\end{array}$ & $\begin{array}{l}11(28,9 \%) \\
17(44,8 \%) \\
10(26,3 \%)\end{array}$ & 0,4070 \\
\hline $\begin{array}{l}\text { Type of surgery } \\
\text { Laparotomy } \\
\text { Laparoscopy }\end{array}$ & $\begin{array}{c}10(71,4 \%) \\
4(28,6 \%)\end{array}$ & $\begin{array}{l}14(36,9 \%) \\
24(63,1 \%)\end{array}$ & 0,0567 \\
\hline $\begin{array}{l}\text { Tumor location } \\
\text { Ascending colon } \\
\text { Transverse colon } \\
\text { Colon descending } \\
\text { Sigmoid colon } \\
\text { Recto-sigmoid colon }\end{array}$ & $\begin{array}{l}6(42,9 \%) \\
0(0,0 \%) \\
0(0,0 \%) \\
6(42,9 \%) \\
2(14,2 \%)\end{array}$ & $\begin{array}{c}8(21,1 \%) \\
8(21,1 \%) \\
10(26,3 \%) \\
8(21,1 \%) \\
4(10,5 \%)\end{array}$ & 0,0346 \\
\hline
\end{tabular}

The data presented indicates that neither the sex of a patient nor the environment does not influence the risk of developing anastomotic leakage, in post-operative period it is maintained the prevalence of male patients and patients from rural areas. Elderly patients seem to benefit from their age, this complication being more frequent in the young patients in our groups. The stage of developed cancer among the groups did not influence the postoperative complications. complication. In contrast, the tumour site has presented significant differences between patients who developed anastomotic leakage compared two those who did not have it: surgical procedures performed for tumours located on transverse and descending colon have not developed postoperative complications at all in this group (figure no. 1).

Figure no. 1. Incidence of anastomotic leakage for different locations of tumour

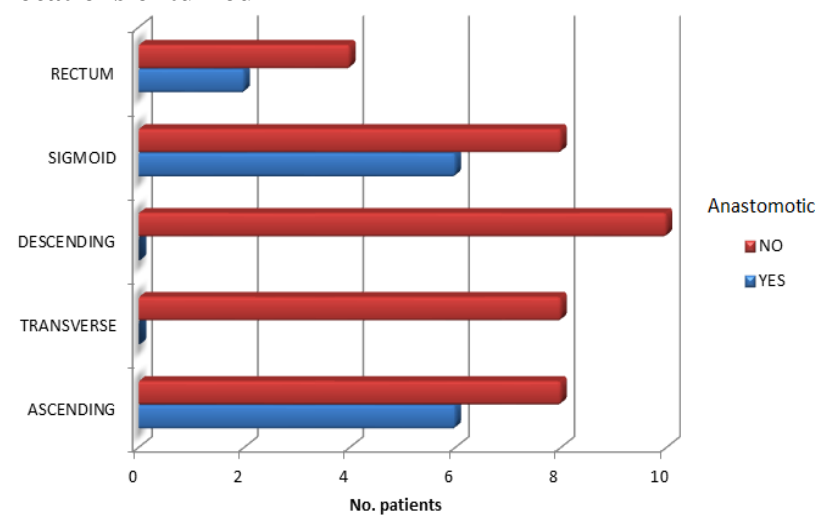

Determination of biological markers have been giving us the results in the two groups of patients (table no. 2). We can 


\section{CLINICAL ASPECTS}

easily observe, from a statistical point of view, that significant differences have been registered in determination of the postoperative period for PCR and the $\mathrm{G} / \mathrm{L}$ rate in the preoperator period. All the other markers have not been valuable in identifying the patients with risk of developing postoperative anastomotic leakage.

Knowing the role of PCR in identifying patients at risk for anastomotic leakage after surgical procedures and seeing the values of the results, we proceeded in analysing the correlation between the modification found in the WBC formula and the perioperative PCR value evolution considering all 104 prelevated biological blood samples. In these conditions we succeeded to demonstrate a strong linear correlation between these two values with an important statistical significance $(\mathrm{r}=0,3083, \mathrm{p}=0,0015)$ (figure no. 2$)$.

Table no. 2. Values of biological markers

\begin{tabular}{|c|c|c|c|}
\hline Biological markers & $\begin{array}{c}\text { Lot A } \\
n=14\end{array}$ & $\begin{array}{c}\text { Lot B } \\
\mathbf{n}=38\end{array}$ & $\begin{array}{c}p \\
\text { (statistical } \\
\text { significance) }\end{array}$ \\
\hline $\begin{array}{ll}\text { TNF- } \alpha \text { - } & \text { average }( \pm \mathrm{DS}) \\
\mathrm{pg} / \mathrm{ml} & \\
& \text { preoperatively } \\
& \text { postoperatively } \\
& \text { day } 1\end{array}$ & $\begin{array}{c}14,41 \\
( \pm 3,2) \\
8,87 \\
( \pm 1,6)\end{array}$ & $\begin{array}{c}13,89 \\
( \pm 11,4) \\
9,75 \\
( \pm 8,9)\end{array}$ & $\begin{array}{l}0,2046 \\
0,5714\end{array}$ \\
\hline $\begin{array}{l}\text { Cortisol - average }( \pm \mathrm{DS}) \\
\mathrm{nmol} / 1 \text { ) } \\
\\
\begin{array}{l}\text { preoperatively } \\
\text { postoperatively } \\
\text { day } 1\end{array}\end{array}$ & $\begin{array}{l}153,99 \\
( \pm 86,3) \\
119,40 \\
( \pm 70,0)\end{array}$ & $\begin{array}{c}143,63 \\
( \pm 137,2) \\
133,24 \\
( \pm 150,8)\end{array}$ & $\begin{array}{l}0,7942 \\
0,7440\end{array}$ \\
\hline $\begin{array}{ll}\mathrm{PCR}-\text { average }( \pm \mathrm{DS}) \\
\mathrm{mg} / \mathrm{dl} & \\
& \begin{array}{l}\text { preoperatively } \\
\text { postoperatively } \\
\text { day } 1\end{array} \\
\end{array}$ & $\begin{array}{c}21,66 \\
( \pm 11,5) \\
87,67 \\
( \pm 53,8) \\
\end{array}$ & $\begin{array}{c}17,80 \\
( \pm 21,2) \\
54,69 \\
( \pm 37,7) \\
\end{array}$ & $\begin{array}{l}0,5232 \\
\mathbf{0 , 0 1 6 5}\end{array}$ \\
\hline $\begin{array}{c}\mathrm{G} / \mathrm{L} \text { ratio - average }( \pm \mathrm{DS}) \\
\text { preoperatively } \\
\text { postoperatively } \\
\text { day } 1\end{array}$ & $\begin{array}{l}10,09 \\
( \pm 7,3) \\
10,94 \\
( \pm 6,6)\end{array}$ & $\begin{array}{c}4,68 \\
( \pm 2,1) \\
9,34 \\
( \pm 7,8)\end{array}$ & $\begin{array}{l}\mathbf{0 , 0 0 3 1} \\
0,1945\end{array}$ \\
\hline
\end{tabular}

TNF- $\alpha=$ tumour necrosis factor alpha, DS $=$ standard deviation, PCR = C-reactive protein, $\mathrm{G} / \mathrm{L}=$ granulocytes/lymphocytes

Figure no. 2. Correlation between pcr and g/l rate in perioperative period

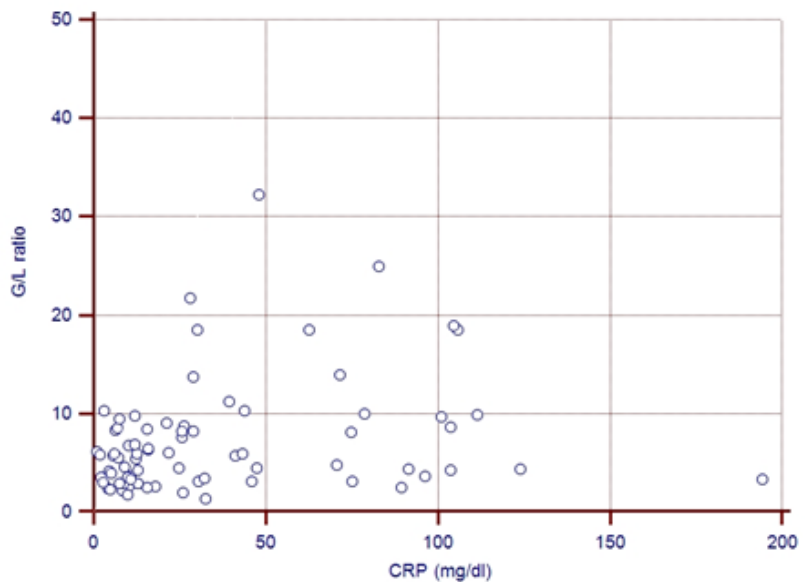

Comparison of the two diagnostic tests for postoperative anastomosis leakage has been accomplished by comparing the two ROC curves (receiver operating characteristic) and AUC (area under curve), meaning the curve for post operative G/L rate and postoperative day 1 PCR level. The results indicated that these two tests are almost identical for $\mathrm{G} / \mathrm{L}$ rate $=0,692$, as for $\mathrm{PCR}=0,691(\mathrm{p}=0,9999)$. For a more accurate identification of the patients with an increased risk for postoperative complication, we have tried to identify some limiting values for these two markers. Analysing ROC curves for both determinations, we found the following limits with best values for sensibility and specificity: for PCR the limit of 71 $\mathrm{mg} / \mathrm{dl}$ with an sensibility of $71,43 \%$ ( IC 95\%: 41,9-91,6) and specificity of $68,42 \%$ ( IC95\%: $51,3-82,5$ ); for G/L rate the 5,8 units with sensibility of $71,43 \%$ ( IC 95\%:41,9-91,6) and specificity of $73,68 \%$ (IC $95 \%$ : 56,9-82,5).

Moreover, we made the observation that all patients with GL rate above 10 units in the postoperative period developed anastomotic leakage. Combining the two criteria $(\mathrm{G} / \mathrm{L}$ rate above 5,8 and postoperative day 1 PCR above 71 $\mathrm{mg} / \mathrm{dl}$ ) does not come with benefits in the sense of increased sensibility, but it becomes an excellent excluding test with a $96,97 \%$ of specificity (IC 95\%: 84,24-99,92\%) and negative predictive value of $80 \%$ (IC 95\%:64,3590,95).

\section{DISCUSSIONS}

The incidence of anastomotic leakage after colorectal cancer surgery varies between $1 \%$ and $40 \%$ depending on the definition of leakage and the type of resection. $(8,9)$ The incidence observed in our study is $26.9 \%$ which is in the average range. This complication is frequently associated with a high mortality rate between $4 \%$ and $15 \%$ and under these circumstances the early diagnosis is very important. But an early diagnosis of an anastomotic leakage is not always easy in immediate postoperative period due to reduced clinical evidence in this period, a fact that may contribute to an increased mortality. The presence of respiratory, neurological and abdominal symptoms will not allow the early diagnosis of anastomotic leakage, because these symptoms usually appear with the beginning of the 4th day after surgery (11) and fever and abdominal sensibility are not specific signs for anastomotic leakage being frequently present due to other causes in the immediate postoperative period.(8) According to Alves \& Amp (12) a late diagnosis of anastomotic leakage (after the 5th day of surgery) is associated with a mortality of $18 \%$, but diagnosed and treated earlier, mortality could decrease under $1 \%$. As a consequence, early detection and treatment of anastomotic leakage is essential and makes the early biological markers become very useful. Tissue ischemia of the suture line at the level of the anastomosis appears to be responsible for early inflammatory response with a release of acute phase proteins (such as PCR).(13,14) Decrease of $\mathrm{pH}$ at the level of mucosa in the anastomotic suture line in the first 24-hours after the surgery increases the risk of dehiscence (15) and sustains the theory that inadequate perfusion in the anastomosis appears in the early phase and increases the risk of complications.

Exponential increase of PCR level in 2-3 days after surgery indicates an increased risk of complications at the level of the suture in patients with other excluded infectious causes (respiratory, urinary or suture cause) (3), but we wanted an earlier marker detection even in the preoperative period which could predict an unwanted evolution of the anastomosis. We have found that $\mathrm{G} / \mathrm{L}$ rate increases in the preoperative period can serve as an indicator for anastomotic leakage with a comparable power as the levels of PCR in post-operative period: a sensitivity of 70 to $80 \%$ and a specificity of 80 to $86 \%$ for PCR above of $140 \mathrm{mg} / \mathrm{dl}$ in the postoperative $3 \mathrm{rd}$ day $(3,13)$ versus sensibility of $71,43 \%$ and specificity of $73.68 \%$ for $\mathrm{G} / \mathrm{L}$ rate above 5,8 unites postoperative.

Considering observations tied to modified WBC formula in different types of stress and inflammation correlated with results of our study we can presume that an increased preoperative $\mathrm{G} / \mathrm{L}$ rate could exist in the presence of a local subclinical inflammation that marks the evolution of 


\section{CLINICAL ASPECTS}

anastomosis in the postoperative period.

\section{CONCLUSIONS}

Early identification of patients with colorectal cancer exposed to anastomotic leakage risk may be careful check-up of biological markers in the immediate postoperative period and early treatment considerably decreasing the mortality due to this complication. Our study brings attention to the importance of GL rate as a marker of inflammation immediately available and accessible. Reprogramming patients seems reasonable if a $\mathrm{G} / \mathrm{L}$ rate is greater than 10 before surgery.

\section{Conflict of interest: No conflict of interests.}

\section{REFERENCES}

1. Straatman J, Harmsen AMK, Cuesta MA, Berkhof J, Jansma EP, van der Peet DL.Predictive Value of CReactive Protein for Major Complications after Major Abdominal Surgery: A Systematic Review and PooledAnalysis. PLoS ONE. 2015;10(7):e0132995.

2. Adamina M, Steffen T, Tarantino I, Beutner U, Schmied $\mathrm{BM}$, Warschkow R. Meta-analysis of the predictive value of C-reactive protein for infectious complications in abdominal surgery. Br J Surg. 2015;102(6):590-8.

3. Almeida AB, Faria G, Moreira H, Pinto-de-Sousa J, Correia-da-Silva P, Maia JC. Elevated serum C-reactive protein as a predictive factor for anastomotic leakage in colorectal surgery. Int J Surg. 2012;10(2):87-91.

4. Tabuchi T, Shimazaki J, Satani T, Nakachi T, Watanabe Y, Tabuchi $\mathrm{T}$. The perioperative granulocyte/lymphocyte ratio is a clinically relevant marker of surgical stress in patients with colorectal cancer. Cytokine. 2011 Feb;53(2):243-8.

5. Ramer-Quinn DS, Baker RA, Sanders VM. Activated T helper 1 and $\mathrm{T}$ helper 2 cells differentially express the $\mathrm{b}-2$ adrenergic receptor. J Immunol. 1997;159:4857-67.

6. Suzuki S, Toyabe S, Moroda T, et al. Circadian rhythm of leukocytes and lymphocyte subsets and its possible correlation with the function of the autonomic nervous system. Clin Exp Immunol. 1997;110:500-8.

7. Zahorec R. Ratio of neutrophil to lymphocyte counts-rapid and simple parameter of systemic inflammation and stress in critically ill. Bratisl Lek Listy. 2001;102(1):5-14.

8. Bellows CF, Webber LS, Albo D, Awad S, Berger DH. Early predictors of anastomotic leaks after colectomy. Tech Coloproctol. 2009;13:41-7.

9. Kingham TP, Pachter HL. Colonic anastomosis leak: risk factors, diagnosis, and treatment. J Am Coll Surg. 2009;208:269-78.

10. Soeters PB, de Zoete JPJGM, Dejong CHC, Williams NS, Baeten CGMI. Colorectal Surgery and Anastomotic Leakage. Digestive Surgery. 2002:150-5.

11. Ortega-Deballon P, Radais F, Facy O, d'Athis P, Masson D, Charles PE, et al. C-reactive protein is an early predictor of septic complications after elective colorectal surgery. World J Surg. 2010;34:808-14.

12. Alves A, Panis Y, Trancart D, Regimbeau JM, Pocard M, Valleur P. Factors associated with clinically significant anastomotic leakage after large bowel resection: multivariate analysis of 707 patients. World J Sur. 2012;26:499-502.

13. Welsch T, Müller SA, Ulrich A, Kischlat A, Hinz U, Kienle P, et al. C-Reactive protein as early predictor for infectious postoperative complications in rectal surgery. Int J Colorectal Dis. 2007;22:1499-507.

14. Attard JA, Raval MJ, Martin GR, Kolb J, Afrouzian M, Buie WD, et al. The effects of systemic hypoxia on colon anastomotic healing: an animal model. Dis Colon Rectum.
2005;48:1460-70.

15. Millan M, Garcia-Granero E, Flor B, Garcia-Botello S, Lledo S. Early prediction of anastomotic leak in colorectal cancer surgery by intramucosal pH. Dis Colon Rectum 2016;49:595-601. 